\title{
EDITORIAL
}

\section{A Joint Venture: ATS and ERS}

\author{
D. Olivieri, ERS president and G. Hunninghake, ATS president
}

The purpose of this letter is to encourage members of the American Thoracic Society (ATS) and the European Respiratory Society (ERS) to continue to develop a more close association. Reciprocal feeling of affinity and respect have existed between many respiratory and critical care physicians in the United States and Europe for a long period of time. Joint projects and other similar relationships of mutual understanding between the ATS and ERS are a more recent development, as are the close and cordial relationships between the ATS Board of Directors and the ERS Executive Committee. It is highly likely that the relationships between these two societies will continue to grow.

The principal motive for the newness of some of these relationships can certainly be explained by the youth of the ERS. Officially, the Society is only four years old and its short history might be of some interest. Until four years ago, there were two separate societies, focussing on pathophysiology and respiratory disease. The first, the Societas Europaea Physiologiae Clinicae Respiratoriae (SEPCR), was primarily concerned with respiratory physiology and pathophysiology. The quality of the research and the knowledge of pathophysiology was excellent. The Societas Europaea Pneumologica (SEP) was more concerned with the problems of clinical pulmonary medicine.

The difficulties that the two societies encountered were augmented by the same characteristics that make Europe so fascinating; ethnic and cultural diversity. A large number of Western and Eastern European countries, all with different languages, were anxious to communicate with each other. A "miracle" occurred 5 years ago, with the merging of the two societies was decided, and the new Society was set up under the able leadership of an Executive Committee.

The first objective of the new society was to create a central office in Paris, following the example of the ATS. The advice of Marilyn Hansen (Executive Director of the ATS) and Rosine Fiévet (Executive Director of the ERS) was invaluable. In no time, the ERS membership (less than 1,000 from the SEPCR and a little more than 1,000 from the SEP) almost doubled. Today, the Society continues to grow and includes not only respiratory medicine physicians, but also Pediatricians, Intensive Care Physicians, Surgeons, and Allergists interested in respiratory medicine.

The second objective was to organize an annual Congress that would be highly regarded by both members of the ERS and nonmembers. Again, the experience of the ATS was indispensable. The recent meeting in Firenze in 1993 was very rewarding and highly successful. More than 6,000 participants attended the meeting and over 2,000 high quality abstracts were presented. The meeting was also an unquestioned social success (is not Tuscany the right place for socializing?).

The third objective was the establishment of an official journal, the European Respiratory Journal. It has not yet reached the level of the "Blue Journal" or the "Red Journal"; however, its impact on respiratory medicine and science is unquestioned and rising at a rapid rate. The recently created Sheffield Office will manage many of the professional publications and educational activities of the Society and will provide the necessary funds to further develop Respiratory Medicine in Europe.

The ERS is now ready to join the ATS in many initiatives that will bring our Societies closer together. These include a reduced fee for joint membership, newsletter information exchanges, annual meeting abstract from exchanges, and joint organization of a World Congress in the year 2000. To these initiatives can be added ongoing scientific programmes that include joint symposia at the ATS and ERS annual meetings, Stop-Smoking campaigns, standardization of infant lung function tests, a common statement on chronic obstructive lung disease, joint therapy for various lung diseases, and discussions related to Critical (Intensive) Care Medicine.

The ATS and ERS are already international societies. Interactions between the ATS, ERS and other Societies will clearly increase with time. We are strongly convinced that collaborations and critical discussions between our members on both sides of the Atlantic can only be advantageous for the scientific and professional interests of the discipline. We write this letter to give our full support to these new relationships. 